\title{
Secondhand smoke exposure and mental health problems in Korean adults
}

\author{
Na Hyun Kim ${ }^{1}$, Hansol Choi ${ }^{1,2}$, Na Rae Kim ${ }^{1,2}$, Jee-Seon Shim ${ }^{2}$, Hyeon Chang Kim ${ }^{2,3}$ \\ ${ }^{1}$ Department of Public Health, Yonsei University Graduate School, Seoul; ${ }^{2}$ Cardiovascular and Metabolic Diseases Etiology Research Center, \\ Yonsei University College of Medicine, Seoul; ${ }^{3}$ Department of Preventive Medicine, Yonsei University College of Medicine, Seoul, Korea
}

OBJECTIVES: To evaluate the association between secondhand smoke exposure (SHSE) and mental health problems among Korean adults.

METHODS: We analyzed data from the 2011 Korean Community Health Survey. From the total of 229,226 participants aged 19 years or above, we excluded 48,679 current smokers, 36,612 former smokers, 3,036 participants with a history of stroke, 2,264 participants with a history of myocardial infarction, 14,115 participants who experienced at least one day in bed per month due to disability, and 855 participants for whom information regarding SHSE or mental health problems was not available. The final analysis was performed with 22,818 men and 100,847 women. Participants were classified into four groups according to the duration of SHSE: none, $<1 \mathrm{hr} / \mathrm{d}, 1-<3 \mathrm{hr} / \mathrm{d}$, and $\geq 3 \mathrm{hr} / \mathrm{d}$. The presence of depressive symptoms, diagnosed depression, and high stress were measured by questionnaire.

RESULTS: After adjusting for demographic factors, lifestyle, and chronic disease, the odds ratio (OR) and 95\% confidence interval (CI) of depressive symptoms with 1-<3 hr/d and $\geq 3 \mathrm{hr} / \mathrm{d}$ SHSE were 1.44 (95\% CI, 1.14 to 1.82 ) and 1.59 (95\% CI, 1.46 to 1.74), respectively. However, SHSE $\geq 3 \mathrm{hr} / \mathrm{d}$ had a higher OR of 1.37 (95\% CI, 1.20 to 1.58) for diagnosed depression. SHSE was also associated with high stress (1-<3 hr/d: OR, 1.56; $95 \%$ CI, 1.38 to $1.76 ; \geq 3 \mathrm{hr} / \mathrm{d}$ : OR, $1.3395 \%$ CI, 1.28 to 1.40). However, the association between SHSE and symptoms of depression and stress did not differ significantly by region.

CONCLUSIONS: SHSE may be associated with mental health problems such as depression and stress in Korean adults.

KEY WORDS: Secondhand smoke, Mental health, Depression, Stress

\section{INTRODUCTION}

Around 58 million non-smokers are exposed to secondhand smoke, according to the Centers for Disease Control and Prevention (CDC) [1], and even a low level of secondhand smoke

Correspondence: Hyeon Chang Kim

Department of Preventive Medicine, Yonsei University College of Medicine, 50-1Yonsei-ro, Seodaemun-gu, Seoul 03722, Korea

Tel: +82-2-2228-1873, Fax: +82-2-392-8133, E-mail: hckim@yuhs.ac

Received: Dec 21, 2015, Accepted: Mar 14, 2016, Published: Mar 16, 2016

This article is available from: http://e-epih.org/

(C) 2016, Korean Society of Epidemiology

(C) This is an open-access article distributed under the terms of the Creative Commons Attribution License (http://creativecommons.org/licenses/by/3.0/), which permits unrestricted use, distribution, and reproduction in any medium, provided the original work is properly cited. exposure (SHSE) causes significant health problems [2]. SHSE is associated with inflammation and cardiovascular disease $[3,4]$. There is also evidence for a detrimental effect of SHSE on mental health in adults [5-9], although some studies do not support this $[10,11]$. Mental illness of extended duration or moderate or severe intensity leads to significant morbidity and reduced daily function, and may be associated with suicide, the incidence of which is increasing in Korea.

The purpose of the present study was to explore the association between SHSE and symptoms of depression and stress in Korean adults who had never been cigarette smokers themselves, using data from the Korean Community Health Survey (KCHS). Our previous studies have reported a positive association between SHSE and mental health problems; however, these studies focused only on depression $[12,13]$. In the present 
study, we hypothesized that SHSE was associated with mental health problems including depressive symptoms, diagnosed depression, and high stress.

\section{MATERIALS AND METHODS}

\section{Study population}

This study is a cross-sectional analysis from the $2011 \mathrm{KCHS}$ organized by the Korea Centers for Disease Control and Prevention (KCDC). The survey enrolled 229,226 adults aged 19 or older from August to October 2011. From the total 229,226 participants aged 19 years or above, we excluded 48,679 current smokers, 36,612 former smokers, 3,036 participants with a history of stroke, 2,264 participants with a history of myocardial infarction, 14,115 participants who experienced at least one day in bed per month due to disability [14], and 855 participants for whom information regarding SHSE or mental health problems was not available. The final analysis was performed with 22,818 men and 100,847 women. This study was approved by the institutional review board (IRB) of KCDC (IRB no. 201105CON-04-C).

\section{Measurements}

A representative population sample for the KCHS is selected annually based on nationwide address data from the Ministry of Public Administration and Security and on data on housing types and the number of households from the Ministry of Land, Transport and Maritime Affairs. Sample households were extracted from these data with the aim of surveying an average of 900 individuals for each health center [15]. The operating committee, specialized subcommittees, and administration office that conducted the survey were formed through a partnership among the KCDC, 16 cities and provinces, 253 health centers, and 36 universities $[15,16]$.

Participants were individually interviewed in their own household by trained interviewers, who conducted one-on-one surveys using a laptop computer. Information was collected about sociodemographic characteristics, health behaviors, and history of chronic disease. Height and weight were measured, and body mass index (BMI) was calculated as weight in kilograms divided by the square of height in meters. Marital status was categorized into three groups: never married, married, and divorced/separated/widowed. Education level was divided into three groups: middle school or lower, high school, and college or higher. Occupation was categorized into four groups: experts, clerical/services roles, simple skilled roles, and unemployed/homemaker. Monthly income was divided into quartiles: $<1.0$ million Korean won (KRW), $1.0-<2.5$ million KRW, $2.5-<4.0$ million KRW, and $\geq 4.0$ million KRW. Exercise was described as those who did severe exercise $\geq 20$ minutes for $\geq 3$ times per week, or those who did moderate exercise $\geq 30$ minutes at least once per week. Regular alcohol consumption was defined as more than five glasses of alcohol for two days per week. A history of hypertension, diabetes, or dyslipidemia was classified as the presence of chronic disease. Sleep time was determined in terms of the number of hours slept each day. SHSE was categorized into four groups: none, $<1 \mathrm{hr} / \mathrm{d}, 1-<3 \mathrm{hr} / \mathrm{d}$, and $\geq 3 \mathrm{hr} / \mathrm{d}$.

\section{Assessment of symptoms of mental illness}

The presence of depressive symptoms were assessed using the question "Have you felt little pleasure or hopeless continuously for over two weeks during the past year, and did this impact on your everyday life?". The presence of diagnosed depression was assessed using the question "Have you ever been diagnosed with depression by a doctor?". Perceived stress was measured by asking participants about whether they experienced a level of stress in daily life that was minimal to mild (low stress) or moderate to severe (high stress).

\section{Statistical analysis}

General characteristics were described for a total of 123,665 participants using an independent t-test and a chi-square test. SHSE and other variables were compared between participants with depressive symptoms, diagnosed depression, or high stress and those without these conditions using an ANOVA and a chisquare test. The association between SHSE and mental health problems was assessed using logistic regression models adjusted for age, gender, BMI, marital status, education level, occupation, monthly income, exercise, regular alcohol consumption, and history of chronic disease. We performed a subgroup analysis to assess whether sociodemographic factors modified the association between SHSE and mental health problems.

We estimated the mean, prevalence, and odds ratio (OR) using sampling weights. Statistical analyses were performed using the PROC SURVEY procedure in SAS version 9.4 (SAS Institute Inc., Cary, NC, USA). All analyses were two-sided and pvalues less than 0.05 were regarded as statistically significant.

\section{RESULTS}

General characteristics are shown by gender in Table 1 . The mean age was significantly higher in women, and the mean BMI was significantly higher in men. Men were more likely to have a higher education level and monthly income, be employed, and to perform regular exercise and be a regular alcohol drinker than women. Women had a higher prevalence of chronic disease than men and a higher prevalence of SHSE (61.2\%), 
Table 1. Basic characteristics by gender $(n=123,665)$

\begin{tabular}{|c|c|c|c|}
\hline Variables & $\operatorname{Men}(n=22,818)$ & Women $(n=100,847)$ & $\mathrm{p}$-value \\
\hline Age (yr) & $45.7 \pm 17.6$ & $49.8 \pm 16.3$ & $<0.001$ \\
\hline Body mass index $\left(\mathrm{kg} / \mathrm{m}^{2}\right)$ & $23.6 \pm 2.9$ & $22.5 \pm 3.1$ & $<0.001$ \\
\hline Sleep time (hr) & $6.65 \pm 1.1$ & $6.66 \pm 1.2$ & $<0.001$ \\
\hline Age (yr) & & & $<0.001$ \\
\hline $19-29$ & $5,460(36.9)$ & $12,201(18.3)$ & \\
\hline $30-39$ & $3,832(19.1)$ & $17,552(20.7)$ & \\
\hline $40-49$ & $4,030(17.3)$ & $20,681(22.6)$ & \\
\hline $50-59$ & $3,778(13.9)$ & $21,098(19.2)$ & \\
\hline $60-69$ & $3,098(7.4)$ & $15,491(11.0)$ & \\
\hline$\geq 70$ & $2,620(5.4)$ & $13,824(8.2)$ & \\
\hline Marital status & & & $<0.001$ \\
\hline Never married & 6,907 (42.9) & $12,504(18.2)$ & \\
\hline Married & $14,676(53.4)$ & $68,609(66.2)$ & \\
\hline Divorced/separated/widowed & $1,219(3.7)$ & $19,663(15.6)$ & \\
\hline Education & & & $<0.001$ \\
\hline Middle school or lower & $5,289(11.9)$ & $42,440(28.3)$ & \\
\hline High school & $10,909(53.1)$ & $42,823(49.8)$ & \\
\hline College or higher & $6,620(35.0)$ & $15,584(22.0)$ & \\
\hline Occupation & & & $<0.001$ \\
\hline Experts & $3,687(19.7)$ & $9,561(12.5)$ & \\
\hline Clerical/services roles & 4,799 (23.9) & $22,262(24.2)$ & \\
\hline Simple skilled roles & $8,052(24.7)$ & $21,008(13.5)$ & \\
\hline Unemployed or housekeeper & $6,236(31.6)$ & $47,924(49.8)$ & \\
\hline Monthly income ( $10^{6}$ Korean won) & & & $<0.001$ \\
\hline$<1.0$ & $5,939(19.8)$ & $30,838(23.0)$ & \\
\hline $1.0-<2.5$ & $6,354(25.3)$ & $27,417(25.7)$ & \\
\hline $2.5-<4.0$ & $5,329(27.1)$ & $22,446(26.2)$ & \\
\hline$\geq 4.0$ & $5,196(27.9)$ & $20,146(25.1)$ & \\
\hline Regular exercise & $5,779(22.1)$ & $21,139(17.8)$ & $<0.001$ \\
\hline Regular alcohol drinker & $2,759(11.9)$ & 2,905 (3.3) & $<0.001$ \\
\hline Hypertension & $3,436(10.2)$ & $19,476(14.1)$ & $<0.001$ \\
\hline Diabetes & $1,326(3.7)$ & $6,084(4.5)$ & $<0.001$ \\
\hline Dyslipidemia & $579(2.0)$ & $4,853(4.4)$ & $<0.001$ \\
\hline Secondhand smoke (hr/d) & & & $<0.001$ \\
\hline None & $12,484(48.1)$ & $42,417(38.7)$ & \\
\hline$<1$ & $4,537(23.3)$ & $36,999(39.2)$ & \\
\hline $1-<3$ & $400(2.0)$ & $1,667(1.6)$ & \\
\hline$\geq 3$ & $5,397(26.6)$ & $19,764(20.4)$ & \\
\hline Depressive symptoms & & & $<0.001$ \\
\hline No & $22,319(97.6)$ & $95,775(94.5)$ & \\
\hline Yes & $493(2.4)$ & $5,030(5.5)$ & \\
\hline Diagnosed depression & & & $<0.001$ \\
\hline No & 22,603 (99.2) & $97,964(97.4)$ & \\
\hline Yes & $210(0.8)$ & $2,857(2.6)$ & \\
\hline Perceived stress & & & $<0.001$ \\
\hline Minimal & $5,119(18.6)$ & $19,372(16.7)$ & \\
\hline Mild & $13,042(58.8)$ & $56,464(57.6)$ & \\
\hline Moderate & 4,212 (20.5) & $22,346(22.9)$ & \\
\hline Severe & $431(2.2)$ & $2,583(2.8)$ & \\
\hline
\end{tabular}

Values are presented as mean \pm standard deviation or number (\%).

depressive symptoms (5.5\%), diagnosed depression (2.6\%), and high stress $(25.7 \%)$ than men.

Table 2 presents the prevalence of depressive symptoms, diagnosed depression, and high stress according to participant characteristics. The prevalence of depressive symptoms and diagnosed depression were higher in participants aged 60 to 69 years, divorced/separated/widowed, educated to the level of middle school or lower, and those who were unemployed or homemakers. The prevalence of high stress was higher in participants aged 30 to 39 years, were never married, educated to a college level or higher, and worked as experts or in a clerical/ services role. Participants with a low monthly income were 


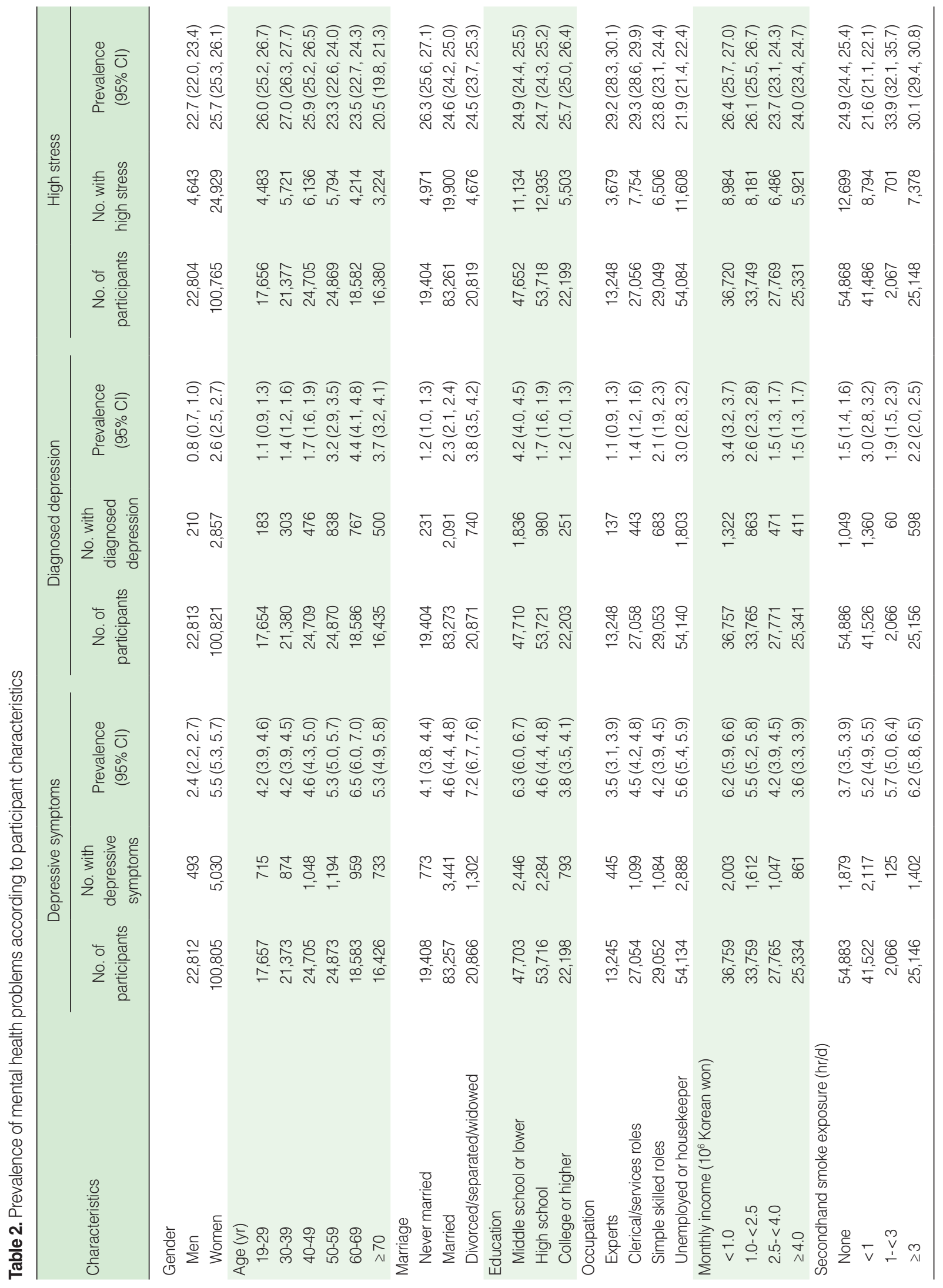


more likely to have mental health problems. Participants experiencing SHSE of $\geq 3 \mathrm{hr} / \mathrm{d}$ had a higher prevalence of depres- sive symptoms (6.2\%), while those with SHSE of $<1 \mathrm{hr} / \mathrm{d}$ were more likely to have diagnosed depression (3.0\%). Meanwhile,
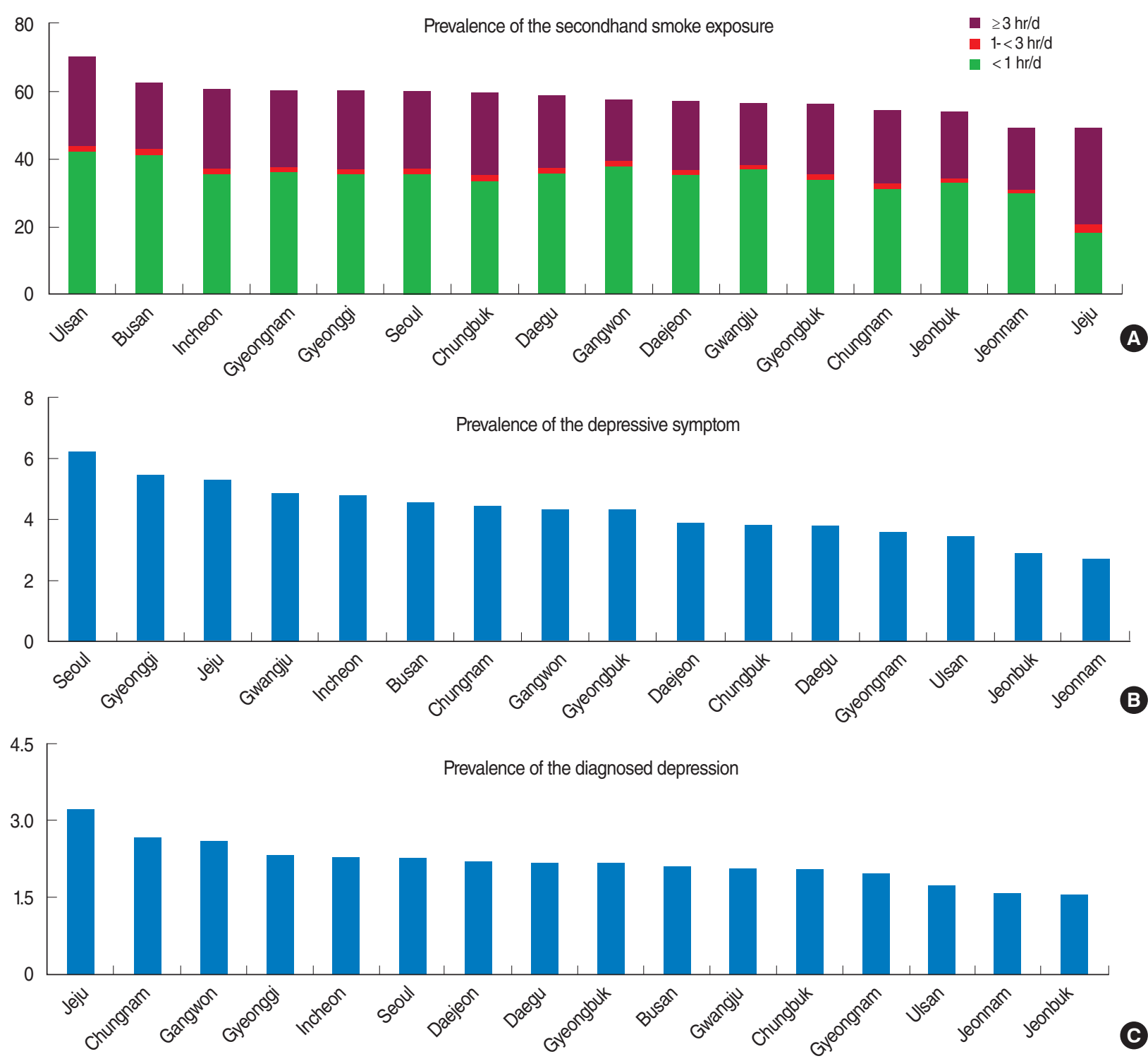

C

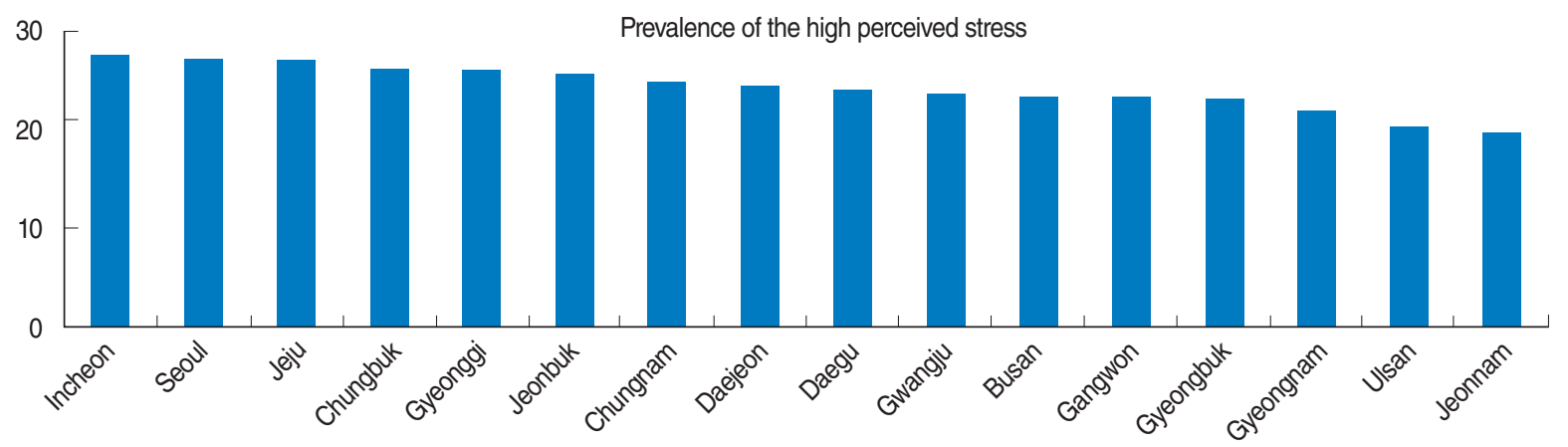

(D)

Figure 1. Prevalence of the secondhand smoke exposure (A) and mental health problems (B: depressive symptom, C: diagnosed depression, and D: high perceived stress) by region. 
participants with SHSE of 1-<3 hr/d had a prevalence of high stress $(33.9 \%)$.

Figure 1 shows that the regional prevalence of SHSE ranged from $49.3 \%$ (Jeju) to $70.4 \%$ (Ulsan). The prevalence of depressive symptoms ranged from $2.7 \%$ (Jeonnam) to $6.2 \%$ (Seoul), while the prevalence of diagnosed depression ranged from
$1.6 \%$ (Jeonbuk) to $3.2 \%$ (Jeju). The prevalence of high stress ranged from $19.6 \%$ (Jeonnam) to $27.6 \%$ (Incheon).

Table 3 describes the association between SHSE and mental health problems in all participants, adjusting for covariates. Compared to participants with no SHSE, those with 1-<3 hr/d SHSE or SHSE of $\geq 3 \mathrm{hr} / \mathrm{d}$ had a higher OR and $95 \%$ confidence in-

Table 3. Association between SHSE and mental health problems in all participants

\begin{tabular}{|c|c|c|c|c|c|c|c|}
\hline \multirow{2}{*}{ SHSE (hr/d) } & \multirow{2}{*}{ Total } & \multicolumn{2}{|c|}{ Depressive symptoms } & \multicolumn{2}{|c|}{ Diagnosed depression } & \multicolumn{2}{|c|}{ High stress } \\
\hline & & $\mathrm{n}(\%)$ & OR $(95 \% \mathrm{Cl})$ & $\mathrm{n}(\%)$ & $\mathrm{OR}(95 \% \mathrm{Cl})$ & $\mathrm{n}(\%)$ & OR $(95 \% \mathrm{Cl})$ \\
\hline \multicolumn{8}{|c|}{ All participants } \\
\hline None & 54,883 & $1,879(3.7)$ & 1.00 & $1,049(1.5)$ & 1.00 & $12,699(24.9)$ & 1.00 \\
\hline$<1$ & 41,522 & 2,117 (5.2) & $0.99(0.88,1.11)$ & $1,360(3.0)$ & $1.15(0.99,1.34)$ & $8,794(21.6)$ & $1.04(0.98,1.11)$ \\
\hline $1-<3$ & 2,066 & $125(5.7)$ & $1.44(1.14,1.82)$ & $60(1.9)$ & $1.11(0.80,1.54)$ & $701(33.9)$ & $1.56(1.38,1.76)$ \\
\hline$\geq 3$ & 25,146 & $1,402(6.2)$ & $1.59(1.46,1.74)$ & $598(2.2)$ & $1.37(1.20,1.58)$ & $7,378(30.1)$ & $1.33(1.28,1.40)$ \\
\hline \multicolumn{8}{|l|}{ Men } \\
\hline None & 12,482 & $197(1.7)$ & 1.00 & $97(0.7)$ & 1.00 & $2,407(21.9)$ & 1.00 \\
\hline$<1$ & 4,537 & $126(2.8)$ & $0.99(0.66,1.48)$ & $71(1.4)$ & $1.00(0.52,1.92)$ & 748 (18.2) & $1.06(0.91,1.25)$ \\
\hline $1-<3$ & 399 & 14 (3.3) & $2.01(1.04,3.86)$ & $2(0.6)$ & $0.83(0.19,3.56)$ & 118 (30.9) & $1.59(1.23,2.04)$ \\
\hline$\geq 3$ & 5,394 & $156(3.2)$ & $1.87(1.43,2.44)$ & $40(0.7)$ & $1.06(0.67,1.69)$ & $1,370(27.4)$ & $1.37(1.25,1.51)$ \\
\hline \multicolumn{8}{|l|}{ Women } \\
\hline None & 42,401 & $1,682(4.4)$ & 1.00 & $952(1.8)$ & 1.00 & $10,292(26.0)$ & 1.00 \\
\hline$<1$ & 36,985 & $1,991(5.6)$ & $0.98(0.87,1.11)$ & $1,289(3.2)$ & $1.16(1.00,1.36)$ & $8,046(22.2)$ & $1.05(0.98,1.12)$ \\
\hline $1-<3$ & 1,667 & $111(6.5)$ & $1.37(1.07,1.75)$ & $58(2.4)$ & $1.14(0.81,1.59)$ & $583(35.0)$ & $1.55(1.35,1.78)$ \\
\hline$\geq 3$ & 19,752 & $1,246(7.3)$ & $1.56(1.42,1.72)$ & $558(2.8)$ & $1.41(1.22,1.63)$ & $6,008(31.2)$ & $1.32(1.26,1.39)$ \\
\hline
\end{tabular}

Adjusted for age, gender, body mass index, marital status, education level, occupation, monthly income, regular exercise, regular alcohol consumption, hypertension, diabetes, dyslipidemia, sleep time.

SHSE, secondhand smoke exposure; OR, odds ratio; $\mathrm{Cl}$, confidence interval.

Between SHSE and diagnosed depression

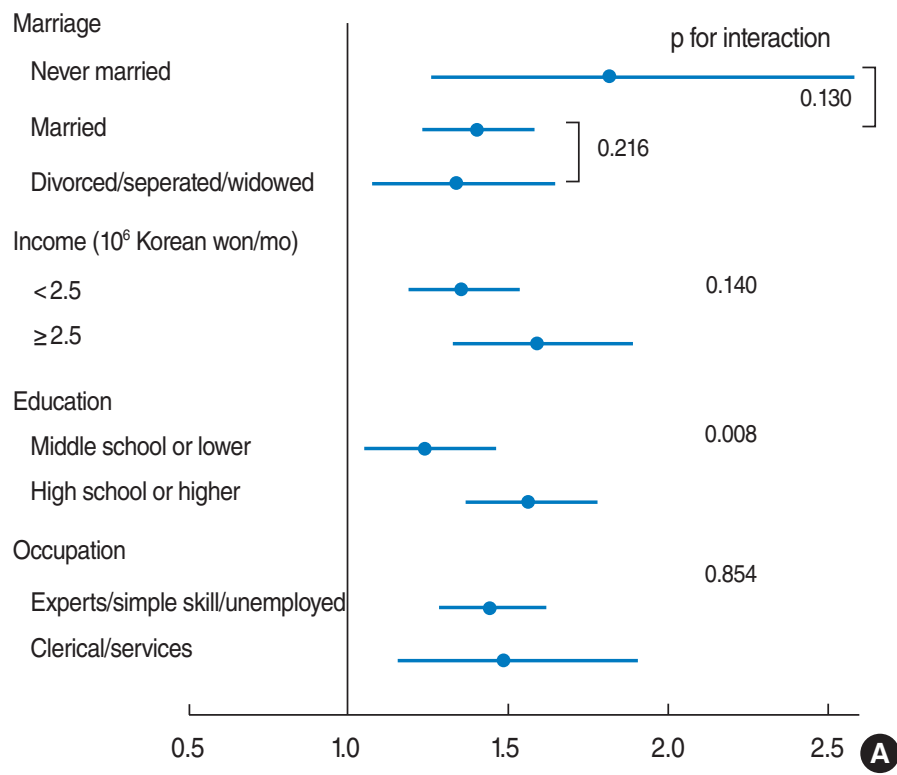

Between SHSE and high stress

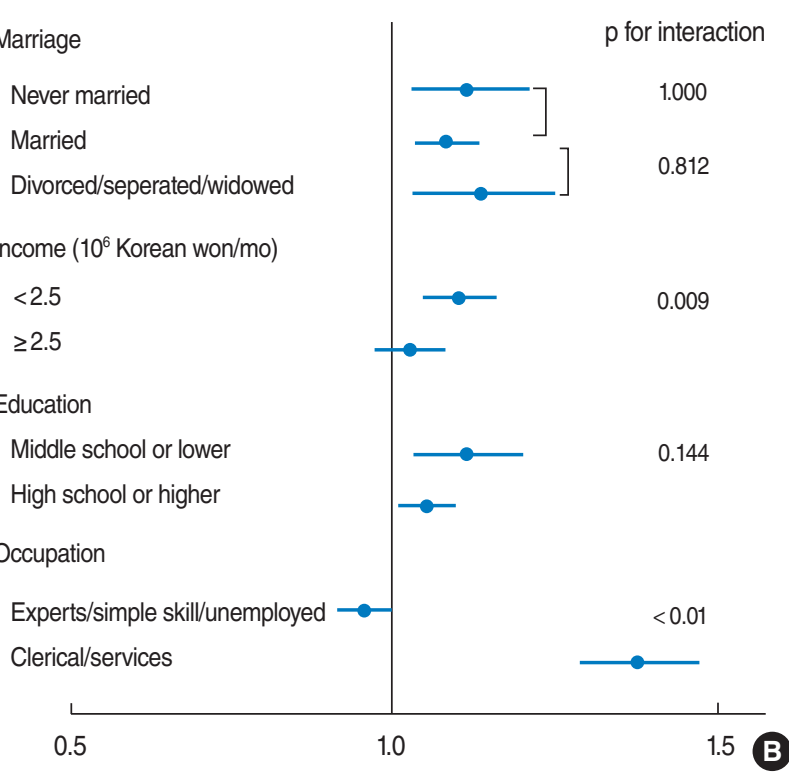

Figure 2. Association between secondhand smoke exposure (SHSE) and mental health problems (A: diagnosed depression, B: high stress) by sociodemographic factors. Odds ratio and 95\% confidence interval adjusted for age, gender, body mass index, marital status, education level, occupation, income, regular exercise, alcohol drinking, hypertension, diabetes, dyslipidemia, sleep time. SHSE was divided into two groups; no SHSE (reference) and SHSE. 
terval (CI) for depressive symptoms 1.44 (95\% CI, 1.14 to 1.82 ) and 1.59 (95\% CI, 1.46 to 1.74), respectively. Participants with SHSE of $\geq 3 \mathrm{hr} / \mathrm{d}$ had an OR of 1.37 (95\% CI, 1.20 to 1.58) for diagnosed depression. SHSE was also associated with high stress (1-<3 hr/d: OR, 1.56; 95\% CI, 1.38 to 1.76; $\geq 3 \mathrm{hr} / \mathrm{d}$ : OR, 1.33; $95 \%$ CI, 1.28 to 1.40 ). In men, SHSE of $1-<3 \mathrm{hr} / \mathrm{d}$ or $\geq 3 \mathrm{hr} / \mathrm{d}$ was significantly associated with depressive symptoms and high stress. In women, SHSE of 1-<3 hr/d or $\geq 3 \mathrm{hr} / \mathrm{d}$ was significantly associated with depressive symptoms and high stress, and women with SHSE $\geq 3 \mathrm{hr} / \mathrm{d}$ had significantly higher odds of diagnosed depression.

We performed a subgroup analysis to assess whether sociodemographic factors modify the association between SHSE and mental health problems. SHSE was associated with marital status, income, education and occupation (Appendix 1). Diagnosed depression was related to income, education, and occupation (Appendix 2), and high stress was associated with marital status, income, education, occupation, and drinking (Appendix 3). Thus, we evaluated the association between SHSE and mental health problems according to these sociodemographic factors (Figure 2).

The association between SHSE and depression was higher in the higher educated group than less educated group (interaction $\mathrm{p}$-value $=0.008$ ).

The association between SHSE and high stress was significantly different according to income status and occupation. The association was higher in the two lower income groups $(<2.5$ million KRW/mo) than the two higher income groups $(\geq 2.5$ million KRW/mo).

In the occupational group of clerical/services roles, the OR of high stress with SHSE was higher than in the other occupational groups (data not shown). To facilitate clear interpretation of this interaction, we re-categorized occupation into two groups: clerical/services roles, and other roles (experts, simple skilled roles, and unemployed or homemakers). The relationship between SHSE and high stress was significantly higher in the new clerical/services roles group than the group of other roles.

Regular alcohol consumption was not independently associated with SHSE or diagnosed depression, and did not affect the association between SHSE and mental health problems (data not shown). As performing further analysis, we found that former and current smokers had higher odds of mental health problems compared to non-smokers (Appendix 4).

\section{DISCUSSION}

We observed a positive association between SHSE and depressive symptoms, diagnosed depression, and high stress in a representative sample of Korean adults. Of note, participants with SHSE of more than three hours had higher odds of these mental health problems compared to those with no SHSE. Men with SHSE of less than an hour or more than three hours had higher odds for depressive symptoms and high stress. However, women with more frequent SHSE mostly had higher odds of the mental health problems examined.

To the best of our knowledge, this is the first report on the association between SHSE and mental health problems in Korean adults, although our previous studies reported the association of SHSE with depression $[12,13]$

Several studies have reported a positive association between SHSE and detrimental effects on mental health. A previous study reported that SHSE, assessed by an objective method, was associated in a dose-dependent manner with psychological distress and risk of future psychiatric illness in a Scottish adult population [5]. Another study based on the US National Health and Nutrition Examination Survey found that SHSE was positively associated with depressive symptoms after adjusting for age, ethnicity, gender, education, and chronic diseases [6]. A recent study also observed that children exposed to secondhand smoke in utero and in childhood had an increased risk of depression in midlife, even after adjusting for direct and indirect exposure to tobacco smoke in adulthood [8]. Another US study reported that persistent SHSE was associated with an increased risk of depression and panic attacks [9]. However, some studies have demonstrated a negative association between SHSE and mental health. SHSE was not associated with depression or mental health in the UK Health and Lifestyle Survey [11], and another study also found no association of SHSE with depression and anxiety in data combined from the Netherlands Study of Depression and Anxiety and the Netherlands Twin Register [10].

There are several possible explanations for the association of SHSE with symptoms of depression and stress among adults. First, secondhand smoke itself can be a chronic stressor for nonsmokers, leading to worsening mental health [17].

Second, there are several plausible biological mechanisms that may explain the association. The dopaminergic system is involved in the pathogenesis of several mental illnesses, including depression [18], and several animal studies suggest that tobacco smoke has acute and long-term effects on the dopamine system. Exposure to tobacco smoke has been reported to elevate dopamine D1 and D2 receptors [19] and alter the expression of gamma-aminobutyric acid B2 receptors, dopamine transporter messenger RNA, and dopamine receptors in the rat brain [20]. Other animal studies indicate that nicotine and tobacco particulate matter influences long-term imbalances of dopamine transport [21], and most importantly that nicotine exposure induces negative mood and decreased mobility in rats [22].

Another biological mechanism that may link SHSE to mental 
illness is chronic inflammation [23,24]. Many studies have proposed that the activation of inflammatory cytokines plays a role in mental illnesses [25]. Cytokines induce the enzyme indoleamine 2,3-dioxygenase, which limits tryptophan and serotonin transporters and may thus cause depression [26].

Even though smoke-free legislation has contributed to a successful decline in SHSE, around $10 \%$ to $15 \%$ of adults continue to be exposed to secondhand smoke at home or workplace [27]. Mental illness imposes an important economic burden, not just on individuals but also on families and communities [28]. Therefore, modifying potential risk factors, for example by monitoring the exposure to secondhand smoke, could not only mitigate the impact of the recession on deaths and injuries arising from suicide, but also reduce economic burden [10].

The present study has several limitations. First, as a cross-sectional study in which all information was gathered at the same point in time, it cannot establish a temporal relationship between SHSE and mental health problems. Second, our use of an interviewer-assisted questionnaire has a limited potential for validation. Therefore, the misclassification bias in measuring SHSE and mental health problems, if any, is likely to be a nondifferential reduction of the association. Third, data on other household members who smoked or on sleep quality were not available in KCHS, but may be potential factors that could influence our data. According to previous studies, living with household members who are smokers could be related to SHSE [29], and sleep quality could be closely associated with mental illness [30].

Lastly, our data included only permanent residents of Korea; therefore, our results may not be generalizable to other countries.

In conclusion, our results suggest that SHSE is associated with depressive symptoms, diagnosed depression, and high stress in a dose-dependent manner among Korean adults, regardless of not only the exposure location but also the region. Since we used a large nationwide representative sample, our findings may be generalizable to the general Korean population. We also observed that sociodemographic factors such as household income and occupation might modify the association between SHSE and mental health problems. Further studies are needed to confirm the causal effects of SHSE on the development and aggravation of mental health problems, and to identify the underlying biological mechanisms.

\section{CONFLICT OF INTEREST}

The authors have no conflicts of interest to declare for this study.

\section{ORCID}

Na Hyun Kim http://orcid.org/0000-0002-9418-9144

Hansol Choi http://orcid.org/0000-0003-4244-6644

Na Rae Kim http://orcid.org/0000-0003-4224-5447

Jee-Seon Shim http://orcid.org/0000-0002-8671-3153

Hyeon Chang Kim http://orcid.org/0000-0001-7867-1240

\section{REFERENCES}

1. Homa DM, Neff LJ, King BA, Caraballo RS, Bunnell RE, Babb SD, et al. Vital signs: disparities in nonsmokers' exposure to secondhand smoke--United States, 1999-2012. MMWR Morb Mortal Wkly Rep 2015;64:103-108.

2. US Department of Health and Human Services. The health consequences of smoking - 50 years of progress: a report of the Surgeon General, 2014 [cited 2016 Apr 3]. Available from: http://www.surgeongeneral.gov/library/reports/50-years-of-progress/.

3. Jefferis BJ, Lowe GD, Welsh P, Rumley A, Lawlor DA, Ebrahim S, et al. Secondhand smoke (SHS) exposure is associated with circulating markers of inflammation and endothelial function in adult men and women. Atherosclerosis 2010;208:550-556.

4. Venn A, Britton J. Exposure to secondhand smoke and biomarkers of cardiovascular disease risk in never-smoking adults. Circulation 2007; 115:990-995.

5. Hamer M, Stamatakis E, Batty GD. Objectively assessed secondhand smoke exposure and mental health in adults: cross-sectional and prospective evidence from the Scottish Health Survey. Arch Gen Psychiatry 2010;67:850-855.

6. Bandiera FC, Arheart KL, Caban-Martinez AJ, Fleming LE, McCollister K, Dietz NA, et al. Secondhand smoke exposure and depressive symptoms. Psychosom Med 2010;72:68-72.

7. Flensborg-Madsen T, von Scholten MB, Flachs EM, Mortensen EL, Prescott E, Tolstrup JS. Tobacco smoking as a risk factor for depression. A 26-year population-based follow-up study. J Psychiatr Res 2011;45:143-149.

8. Elmasry H, Goodwin RD, Terry MB, Tehranifar P. Early life exposure to cigarette smoke and depressive symptoms among women in midlife. Nicotine Tob Res 2014;16:1298-1306.

9. Taha F, Goodwin RD. Secondhand smoke exposure across the life course and the risk of adult-onset depression and anxiety disorder. $\mathrm{J}$ Affect Disord 2014;168:367-372.

10. Bot M, Vink JM, Willemsen G, Smit JH, Neuteboom J, Kluft C, et al. Exposure to secondhand smoke and depression and anxiety: a report from two studies in the Netherlands. J Psychosom Res 2013;75: 431-436.

11. Lam E, Kvaavik E, Hamer M, Batty GD. Association of secondhand smoke exposure with mental health in men and women: cross-sectional and prospective analyses using the U.K. Health and Lifestyle Survey. Eur Psychiatry 2013;28:276-281.

12. Kim NH, Kim HC, Lee JY, Lee JM, Suh I. Association between environmental tobacco smoke and depression among Korean women. BMJ Open 2015;5:e007131.

13. Lee KJ. Current smoking and secondhand smoke exposure and depression among Korean adolescents: analysis of a national cross-sectional survey. BMJ Open 2014;4:e003734.

14. Statistics Korea. Result of social survey, 2014 [cited 2016 Apr 3]. 
Available from: http://kostat.go.kr/portal/korea/kor_nw/2/6/3/index. board (Korean)

15. Kim YT, Choi BY, Lee KO, Kim H, Chun JH, Kim SY, et al. Overview of Korean Community Health Survey. J Korean Med Assoc 2012; 55:74-83 (Korean).

16. Oh DH, Kim SA, Lee HY, Seo JY, Choi BY, Nam JH. Prevalence and correlates of depressive symptoms in Korean adults: results of a 2009 Korean Community Health Survey. J Korean Med Sci 2013;28: 128-135.

17. Hammen C. Stress and depression. Annu Rev Clin Psychol 2005;1: 293-319.

18. Dailly E, Chenu F, Renard CE, Bourin M. Dopamine, depression and antidepressants. Fundam Clin Pharmacol 2004;18:601-607.

19. Bahk JY, Li S, Park MS, Kim MO. Dopamine D1 and D2 receptor mRNA up-regulation in the caudate-putamen and nucleus accumbens of rat brains by smoking. Prog Neuropsychopharmacol Biol Psychiatry 2002;26:1095-1104.

20. Li S, Kim KY, Kim JH, Kim JH, Park MS, Bahk JY, et al. Chronic nicotine and smoking treatment increases dopamine transporter mRNA expression in the rat midbrain. Neurosci Lett 2004;363:29-32.

21. Danielson K, Putt F, Truman P, Kivell BM. The effects of nicotine and tobacco particulate matter on dopamine uptake in the rat brain. Synapse 2014;68:45-60.

22. Iñiguez SD, Warren BL, Parise EM, Alcantara LF, Schuh B, Maffeo ML, et al. Nicotine exposure during adolescence induces a depression-like state in adulthood. Neuropsychopharmacology 2009;34:
1609-1624.

23. Adams T, Wan E, Wei Y, Wahab R, Castagna F, Wang G, et al. Secondhand smoking is associated with vascular inflammation. Chest 2015;148:112-119.

24. Jefferis BJ, Lowe GD, Welsh P, Rumley A, Lawlor DA, Ebrahim S, et al. Secondhand smoke (SHS) exposure is associated with circulating markers of inflammation and endothelial function in adult men and women. Atherosclerosis 2010;208:550-556.

25. Dowlati Y, Herrmann N, Swardfager W, Liu H, Sham L, Reim EK, et al. A meta-analysis of cytokines in major depression. Biol Psychiatry 2010;67:446-457.

26. Dantzer R, O'Connor JC, Lawson MA, Kelley KW. Inflammationassociated depression: from serotonin to kynurenine. Psychoneuroendocrinology 2011;36:426-436.

27. Centers for Disease Control and Prevention (CDC). Disparities in secondhand smoke exposure--United States, 1988-1994 and 19992004. MMWR Morb Mortal Wkly Rep 2008;57:744-747.

28. World Health Organization. Impact of economic crises on mental health [cited 2016 Apr 3]. Available from: http://www.euro.who.int/ data/assets/pdf file/0008/134999/e94837.pdf.

29. Ho SY, Lai HK, Wang MP, Lam TH. Exposure to secondhand smoke and academic performance in non-smoking adolescents. J Pediatr 2010;157:1012-1017.

30. Stein MB, Belik SL, Jacobi F, Sareen J. Impairment associated with sleep problems in the community: relationship to physical and mental health comorbidity. Psychosom Med 2008;70:913-919. 
Epidemiology and Health 2016;38:e2016009

Appendix 1. Factors associated with secondhand smoke exposure (SHSE)

\begin{tabular}{|c|c|c|c|c|c|}
\hline \multirow{2}{*}{ Variables $(n=123,665)$} & \multicolumn{3}{|c|}{ SHSE } & \multicolumn{2}{|c|}{ Odds ratio ( $95 \%$ confidence interval) } \\
\hline & No & Yes & $p$-value & Unadjusted & Gender, age -adjusted \\
\hline Age (yr) & & & $<0.001$ & & \\
\hline $19-39$ & $16,702(30.4)$ & $22,343(32.5)$ & & 1.00 & 1.00 \\
\hline $40-59$ & $24,001(43.7)$ & $25,586(37.2)$ & & $0.85(0.83,0.89)$ & $0.82(0.79,0.84)$ \\
\hline$\geq 60$ & $14,198(25.9)$ & $20,865(30.3)$ & & $1.67(1.60,1.73)$ & $1.59(1.53,1.65)$ \\
\hline Gender & & & $<0.001$ & & \\
\hline Men & $12,484(22.7)$ & $10,334(15.0)$ & & 1.00 & 1.00 \\
\hline Women & $42,417(77.3)$ & $58,430(85.0)$ & & $1.46(1.41,1.52)$ & $1.43(1.37,1.48)$ \\
\hline Marriage & & & $<0.001$ & & \\
\hline Never married & $8,565(15.6)$ & $10,846(15.8)$ & & 1.00 & 1.00 \\
\hline Married & $37,593(68.5)$ & $45,692(66.5)$ & & $1.00(0.96,1.03)$ & $0.75(0.71,0.79)$ \\
\hline Divorced/separated/widowed & $8,701(15.9)$ & $12,181(17.7)$ & & $1.20(1.14,1.26)$ & $0.76(0.71,0.81)$ \\
\hline Income per month ( $10^{4}$ Korean won) & & & $<0.001$ & & \\
\hline$\geq 4.0$ & $12,413(22.6)$ & $12,929(18.8)$ & & 1.00 & 1.00 \\
\hline$<1.0$ & $16,088(29.3)$ & $20,689(30.1)$ & & $1.53(1.47,1.60)$ & $1.46(1.40,1.53)$ \\
\hline $1.0-<2.5$ & $14,487(26.4)$ & $19,284(28.0)$ & & $1.42(1.36,1.49)$ & $1.40(1.34,1.46)$ \\
\hline $2.5-<4.0$ & $11,913(21.7)$ & $15,862(23.1)$ & & $1.28(1.23,1.34)$ & $1.28(1.22,1.34)$ \\
\hline Education & & & $<0.001$ & & \\
\hline Middle school or lower & 20,501 (37.3) & $27,228(39.6)$ & & 1.00 & 1.00 \\
\hline High school & $21,968(40.0)$ & $31,764(46.2)$ & & $0.83(0.80,0.86)$ & $0.81(0.78,0.85)$ \\
\hline College or higher & $12,432(22.6)$ & $9,772(14.2)$ & & $0.41(0.40,0.43)$ & $0.41(0.39,0.43)$ \\
\hline Occupation & & & $<0.001$ & & \\
\hline Unemployed or housekeeper & $8,023(14.6)$ & $46,137(67.2)$ & & 1.00 & 1.00 \\
\hline Experts & $10,129(18.5)$ & $3,119(4.5)$ & & $0.05(0.04,0.05)$ & $0.04(0.04,0.05)$ \\
\hline Clerical/services & $16,823(30.7)$ & $10,238(14.9)$ & & $0.08(0.08,0.09)$ & $0.08(0.08,0.08)$ \\
\hline Simple skill & $19,855(36.2)$ & $9,205(13.4)$ & & $0.09(0.09,0.10)$ & $0.09(0.09,0.10)$ \\
\hline Drinking & & & $<0.001$ & & \\
\hline Regular alcohol drinkers & $2,710(4.9)$ & 2,954 (4.3) & & $0.83(0.78,0.89)$ & $0.95(0.88,1.01)$ \\
\hline
\end{tabular}

Values are presented as number (\%). 
Appendix 2. Factors associated with diagnosed depression

\begin{tabular}{|c|c|c|c|c|c|}
\hline \multirow{2}{*}{ Variables $(n=123,665)$} & \multicolumn{3}{|c|}{ Diagnosed depression } & \multicolumn{2}{|c|}{ Odds ratio (95\% confidence interval) } \\
\hline & No & Yes & p-value & Unadjusted & Gender, age -adjusted \\
\hline Age (yr) & & & $<0.001$ & & \\
\hline $19-39$ & $38,548(32.0)$ & 486 (15.9) & & 1.00 & 1.00 \\
\hline $40-59$ & $48,265(40.0)$ & $1,314(42.8)$ & & $1.99(1.76,2.26)$ & $1.82(1.61,2.07)$ \\
\hline$\geq 60$ & $33,754(28.0)$ & $1,267(41.3)$ & & $3.46(3.03,3.94)$ & $3.13(2.75,3.57)$ \\
\hline Gender & & & $<0.001$ & & \\
\hline Men & $22,603(18.8)$ & $210(6.9)$ & & 1.00 & 1.00 \\
\hline Women & $97,964(81.3)$ & $2,857(93.2)$ & & $3.17(2.63,3.81)$ & $2.74(2.28,3.29)$ \\
\hline Marriage & & & $<0.001$ & & \\
\hline Never married & $19,173(15.9)$ & $231(7.5)$ & & 1.00 & 1.00 \\
\hline Married & $81,182(67.4)$ & $2,091(68.3)$ & & $1.96(1.66,2.31)$ & $0.93(0.77,1.12)$ \\
\hline Divorced/separated/widowed & $20,131(16.7)$ & $740(24.2)$ & & $3.37(2.80,4.05)$ & $1.02(0.80,1.30)$ \\
\hline Income per month ( $10^{4}$ Korean won) & & & $<0.001$ & & \\
\hline$\geq 4.0$ & $24,930(20.7)$ & $411(13.4)$ & & 1.00 & 1.00 \\
\hline$<1.0$ & $35,435(29.4)$ & $1,322(43.1)$ & & $2.38(2.07,2.73)$ & $1.71(1.47,1.99)$ \\
\hline $1.0-<2.5$ & $32,902(27.3)$ & $863(28.1)$ & & $1.76(1.53,2.03)$ & $1.59(1.37,1.83)$ \\
\hline $2.5-<4.0$ & $27,300(22.6)$ & $471(15.4)$ & & $1.02(0.87,1.20)$ & $1.01(0.85,1.19)$ \\
\hline Education & & & $<0.001$ & & \\
\hline Middle school or lower & $45,874(38.1)$ & $1,836(59.9)$ & & 1.00 & 1.00 \\
\hline High school & $52,741(43.7)$ & $980(32.0)$ & & $0.40(0.36,0.44)$ & $0.58(0.50,0.67)$ \\
\hline College or higher & $21,952(18.2)$ & $251(8.2)$ & & $0.26(0.22,0.31)$ & $0.42(0.34,0.51)$ \\
\hline Occupation & & & $<0.001$ & & \\
\hline Unemployed or housekeeper & $52,337(43.5)$ & $1,803(58.8)$ & & 1.00 & 1.00 \\
\hline Experts & $13,111(10.9)$ & $137(4.5)$ & & $0.36(0.29,0.43)$ & $0.52(0.42,0.64)$ \\
\hline Clerical/services & $26,615(22.1)$ & $443(14.5)$ & & $0.46(0.40,0.53)$ & $0.59(0.51,0.67)$ \\
\hline Simple skill & $28,370(23.6)$ & $683(22.3)$ & & $0.70(0.62,0.79)$ & $0.78(0.69,0.89)$ \\
\hline Drinking & & & 0.004 & & \\
\hline Regular alcohol drinkers & $5,557(4.61)$ & $107(3.49)$ & & $0.69(0.55,0.87)$ & $1.10(0.87,1.39)$ \\
\hline
\end{tabular}

Values are presented as number (\%). 
Appendix 3. Factors associated with high stress

\begin{tabular}{|c|c|c|c|c|c|}
\hline \multirow{2}{*}{ Variables $(n=123,665)$} & \multicolumn{3}{|c|}{ High stress } & \multicolumn{2}{|c|}{ Odds ratio (95\% confidence interval) } \\
\hline & No & Yes & $\mathrm{p}$-value & Unadjusted & Gender, age -adjusted \\
\hline Age (yr) & & & $<0.001$ & & \\
\hline $19-39$ & $28,829(30.7)$ & $10,204(34.5)$ & & 1.00 & 1.00 \\
\hline $40-59$ & $37,644(40.1)$ & $11,930(40.3)$ & & $0.91(0.88,0.94)$ & $0.89(0.86,0.92)$ \\
\hline$\geq 60$ & $27,524(29.3)$ & $7,438(25.2)$ & & $0.79(0.76,0.83)$ & $0.76(0.74,0.81)$ \\
\hline Gender & & & $<0.001$ & & \\
\hline Men & $18,161(19.3)$ & $4,643(15.7)$ & & 1.00 & 1.00 \\
\hline Women & $75,836(80.7)$ & 24,929 (84.3) & & $1.18(1.13,1.23)$ & $1.23(1.17,1.28)$ \\
\hline Marriage & & & $<0.001$ & & \\
\hline Never married & $14,433(15.4)$ & $4,971(16.8)$ & & 1.00 & 1.00 \\
\hline Married & $63,361(67.5)$ & $19,900(67.4)$ & & $0.91(0.88,0.95)$ & $1.03(0.98,1.08)$ \\
\hline Divorced/separated/widowed & $16,143(17.2)$ & 4,676 (15.8) & & $0.91(0.86,0.96)$ & $1.10(1.02,1.19)$ \\
\hline Income per month ( $10^{4}$ Korean won) & & & $<0.001$ & & \\
\hline$\geq 4.0$ & $19,410(20.7)$ & $5,921(20.0)$ & & 1.00 & 1.00 \\
\hline$<1.0$ & $27,736(29.5)$ & $8,984(30.4)$ & & $1.13(1.08,1.19)$ & $1.24(1.17,1.30)$ \\
\hline $1.0-<2.5$ & $25,568(27.2)$ & $8,181(27.7)$ & & $1.12(1.07,1.17)$ & $1.14(1.09,1.20)$ \\
\hline $2.5-<4.0$ & $21,283(22.6)$ & $6,486(21.9)$ & & $0.98(0.94,1.03)$ & $0.98(0.93,1.03)$ \\
\hline Education & & & 0.050 & & \\
\hline Middle school or lower & $36,518(38.9)$ & $11,134(37.7)$ & & 1.00 & 1.00 \\
\hline High school & $40,783(43.4)$ & $12,935(43.7)$ & & $0.99(0.95,1.03)$ & $0.80(0.76,0.84)$ \\
\hline College or higher & $16,696(17.8)$ & $5,503(18.6)$ & & $1.04(0.99,1.09)$ & $0.86(0.81,0.91)$ \\
\hline Occupation & & & $<0.001$ & & \\
\hline Unemployed or housekeeper & $42,476(45.2)$ & 11,608 (39.3) & & 1.00 & 1.00 \\
\hline Experts & $9,569(10.2)$ & $3,679(12.5)$ & & $1.47(1.40,1.55)$ & $1.47(1.40,1.55)$ \\
\hline Clerical/services & $19,302(20.6)$ & $7,754(26.2)$ & & $1.47(1.42,1.54)$ & $1.46(1.40,1.52)$ \\
\hline Simple skill & $22,543(24.0)$ & $6,506(22.0)$ & & $1.11(1.06,1.16)$ & $1.18(1.13,1.24)$ \\
\hline Drinking & & & $<0.001$ & & \\
\hline Regular alcohol drinkers & $3,978(4.23)$ & $1,683(5.69)$ & & $1.40(1.31,1.50)$ & $1.46(1.36,1.57)$ \\
\hline
\end{tabular}

Values are presented as number (\%).

Appendix 4. Association between smoking status and mental health problems in total participants

\begin{tabular}{|c|c|c|c|c|c|c|c|}
\hline Smoking status & Total & \multicolumn{2}{|c|}{ Depressive symptoms } & \multicolumn{2}{|c|}{ Diagnosed depression } & \multicolumn{2}{|c|}{ High stress } \\
\hline \multicolumn{8}{|l|}{ Total participants } \\
\hline Non-smokers & 123,617 & $5,523(4.8)$ & 1.00 & 3067 (2.2) & 1.00 & $29,572(25.0)$ & 1.00 \\
\hline Former smokers & 31,988 & 961 (3.4) & $1.58(1.41,1.78)$ & $466(1.4)$ & $1.81(1.52,2.15)$ & 6,982 (24.7) & $1.21(1.15,1.27)$ \\
\hline Current smokers & 44,491 & $1,807(4.3)$ & $1.92(1.73,2.14)$ & $582(1.3)$ & $1.89(1.59,2.26)$ & $14,099(34.5)$ & $1.75(1.67,1.83)$ \\
\hline \multicolumn{8}{|l|}{ Men } \\
\hline Non-smokers & 22,812 & $493(2.4)$ & 1.00 & $210(0.8)$ & 1.00 & 4,643 (22.7) & 1.00 \\
\hline Former smokers & 29,962 & 758 (2.9) & $1.31(1.12,1.53)$ & 341 (1.1) & $1.36(1.06,1.74)$ & 6,301 (24.0) & $1.13(1.07,1.19)$ \\
\hline Current smokers & 41,447 & 1,373 (3.6) & $1.58(1.38,1.81)$ & 347 (0.8) & $1.16(0.92,1.47)$ & 12,775 (33.8) & $1.63(1.55,1.72)$ \\
\hline \multicolumn{8}{|l|}{ Women } \\
\hline Non-smokers & 100,805 & $5,030(5.5)$ & 1.00 & 2,857 (2.6) & 1.00 & $24,929(25.7)$ & 1.00 \\
\hline Former smokers & 2,026 & $203(10.4)$ & $1.70(1.42,2.04)$ & $125(5.3)$ & $1.88(1.48,2.39)$ & $681(33.8)$ & $1.42(1.26,1.60)$ \\
\hline Current smokers & 3,044 & $434(15.7)$ & $2.55(2.22,2.93)$ & 235 (8.2) & $2.95(2.47,3.54)$ & $1,324(45.5)$ & $2.13(1.93,2.34)$ \\
\hline
\end{tabular}

Values are presented as number (\%) or odds ratio (95\% confidence interval).

Adjusted for age, gender, body mass index, marital status, education level, occupation, income, regular exercise, alcohol drinking, hypertension, diabetes, dyslipidemia, sleep time. 